\title{
COST-EFFECTIVENESS ANALYSIS OF CEFTRIAXONE-AZITHROMYCIN COMBINATION AND SINGLE LEVOFLOXACIN AS EMPIRICAL ANTIBIOTICS IN COMMUNITY-ACQUIRED PNEUMONIA INPATIENTS AT PERSAHABATAN HOSPITAL
}

\author{
SRI SURATINI ${ }^{1}$, RANI SAURIASARI ${ }^{1 *}$, FIRZAWATI HAMADAH ${ }^{2}$, TRI KUSUMAENI ${ }^{3}$ \\ ${ }^{1}$ Department of Pharmacy, Faculty of Pharmacy, Universitas Indonesia, Depok, Indonesia. ${ }^{2}$ Department of Health, Regional General \\ Hospital Bekasi, Bekasi, Indonesia. ${ }^{3}$ Department of Pharmacy, Persahabatan Hospital, Jakarta, Indonesia. Email: rani@farmasi.ui.ac.id
}

Received: 21 April 2017, Revised and Accepted: 13 July 2017

\section{ABSTRACT}

Objective: Community-acquired pneumonia (CAP) is one of the most common infectious diseases. Its prevalence is especially concerning, as the disease severely impacts health and has a high mortality rate. Although antibiotics have been used to treat CAP, their use is often costly and inefficient. Thus, this study aimed to determine the cost-effectiveness of using ceftriaxone-azithromycin combination and single levofloxacin as empirical antibiotics to treat patients with CAP. Cost-effectiveness was analyzed by comparing the direct total medical cost to clinical effectiveness, which was indicated by the respective success rates in each treatment group.

Methods: This study was conducted at Persahabatan Hospital in Jakarta and employed an observational study design, where data were obtained retrospectively from the secondary data contained in medical records for 2014-2016. A total of 100 patients were included in the analysis, with 64 patients using intravenous (iv) antibiotic ceftriaxone and oral azithromycin and 36 patients using iv single levofloxacin.

Results: The median costs of antibiotics were significantly different between the ceftriaxone-azithromycin group and the levofloxacin group: Rp.130.756 and Rp.286.952, respectively. The direct total medical cost in the ceftriaxone-azithromycin group (Rp.6.494.998) was higher than that of the single levofloxacin group (Rp.5.444.242). The success rate was $95.3 \%$ in the ceftriaxone-azithromycin group and $97.2 \%$ in the levofloxacin group, but there were no significant differences between the two groups. The medians for the length of stay (LOS) and length of stay antibiotic-related (LOSAR) measures in the levofloxacin group were 6 and 5 days, which were shorter than the LOS and LOSAR medians in the ceftriaxone-azithromycin group: 7 days and 6 days, respectively. The average cost-effectiveness ratio value in the levofloxacin group was 56.011\% effectiveness lower than that of the ceftriaxone-azithromycin group, which was Rp.68.153\% effectiveness.

Conclusions: Based on these results, it can be concluded that levofloxacin is more cost-effective than a combination of ceftriaxone-azithromycin for treating CAP.

Keywords: Cost-effectiveness, Antibiotic, Community-acquired pneumonia, Ceftriaxone, Azithromycin, Levofloxacin.

(C) 2017 The Authors. Published by Innovare Academic Sciences Pvt Ltd. This is an open access article under the CC BY license (http://creativecommons. org/licenses/by/4. 0/) DOI: http://dx.doi.org/10.22159/ajpcr.2017.v10s5.23112

\section{INTRODUCTION}

In the transition of global epidemics from communicable diseases to non-communicable diseases, developing countries carry a double burden in health. Despite the conclusion of the millennium development goals era, developing countries continue to experience problems with communicable diseases such as diarrhea, tuberculosis, HIV/AIDS, and pneumonia. Community-acquired pneumonia (CAP) is one of the most common infectious diseases. Its prevalence is especially concerning because the disease causes severe health problems and has a high mortality rate. Moreover, treating the disease constitutes a significant financial burden because of the high costs of a health service, especially staying in the hospital, which represents $70-90 \%$ of the total medical cost [1].

The total medical cost for patients with pneumonia in 2005 in the United States of America was about $\$ 40$ million, with $\$ 34$ million reflecting direct cost [2]. Pneumonia is one of the seven most common causes of death in the US, where it is estimated that there are 4 million cases of CAP every year, resulting in 10 million doctor visits, 1 million cases of inpatient care, and 45000 deaths [3]. In Indonesia, pneumonia represents one of big ten conditions requiring inpatient care, with case proportions of $53.95 \%$ male and $46.05 \%$ female and a $7.6 \%$ crude fatality rate, which is higher than other diseases. According to Riskedas, in 2013, there was an increasing inclination of pneumonia period prevalence in all ages: From $2.1 \%$ in 2007 to $2.7 \%$ in 2013 . The five provinces that had the highest pneumonia incidence and prevalence for all ages were East Nusa Tenggara (4.6\% and 10.3\%), Papua (2.6\% and $8.2 \%$ ), Central Sulawesi (2.3\% and 5.7\%), West Sulawesi (3.1\% and 6.1\%), and South Sulawesi (2.4\% and 4.8\%) [4].

In Indonesia, the National Health Insurance (JKN) uses the Indonesia Case-based Groups (INA-CBG) payment system for higher level healthcare facilities. Hospitals are paid based on the INA-CBG tariffs, which reflect the mean cost spent for a diagnosis group. Community-acquired pneumonia is included in the INA-CBG group in the disease class of simple pneumonia and whooping cough. According to the data from Indonesia National Health Insurance, pneumonia is one of the ten highest costing inpatient care conditions for JKN. Antibiotics are integral for treating infectious diseases. Because of increasing health-care costs and limited resources, policymakers, and health-care personnel could benefit from a study examining the cost effectiveness of antibiotics. Pharmacoeconomic evaluation is done to analyze the cost effectiveness of antibiotics and to understand whether antibiotics provide a good treatment outcome at a minimal cost.

According to the Infectious Disease Society of America (IDSA), the American Thoracic Society (ITS), and the Indonesia Society of Respirology (PDPI), the antibiotics used for treating CAP during inpatient care are from the beta-lactam group and are combined with macrolide or single respiratory quinolone antibiotics [5]. In 
Indonesia, for JKN service, there is a significant different in price between the two antibiotic choices. Thus, the pharmacoeconomic analysis is needed to determine the cost-effectiveness of each option. Bhavnani and Ambrose compared gemifloxacin quinolone antibiotics to ceftriaxone-clarithromycin combination antibiotics and found that gemifloxacin is more cost-effective than ceftriaxone-clarithromycin combination [6]. Dresser et al. compared gatifloxacin-quinolone antibiotics to ceftriaxone-macrolide combination antibiotics and also stated that the quinolone antibiotics were more cost-effective than the beta-lactam-macrolide combination antibiotics [7]. This study was performed at Persahabatan Hospital, which is a Class A Government General Hospital and National Referral Hospital for respiratory health located in East Jakarta. This study sought to determine the costeffectiveness of ceftriaxone-azithromycin combination and single levofloxacin as empirical antibiotics for the treatment of inpatients with pneumonia.

\section{METHODS}

This study is an observational study, where data were obtained retrospectively from secondary data (patients' medical records). The results of this study are provided in descriptive and analytical forms. This study was conducted at Persahabatan Hospital. The participants in this study were patients who had been diagnosed with CAP, had received inpatient care, and had been given empirical antibiotic therapy, as written in their medical records from 2014 to 2016 in Persahabatan Hospital.

Samples were only chosen if the patients met the following inclusion criteria: (1) Patients who received inpatient care and main diagnosis of CAP. The diagnosis of pneumonia was made based on signs and symptoms as well as adjunctive examination such as laboratory results or Roentgen photos, (2) adult patients above 18 years old, (3) patients who received ceftriaxone-azithromycin combination or single levofloxacin as empirical antibiotics to treat their CAP, and (4) patients with National Health Insurance (JKN) who had done one therapy cycle (i.e., patient who were not forcibly discharged). Exclusion criteria included the following: (1) Pregnant patients, (2) patients with other infections, and (3) patients with incomplete medical records.

Univariate analysis was used to describe patients' demographic data, which was then presented in tables. Bivariate analysis was used to understand patients' characteristic differences in each empirical antibiotic group and determine the relationship between the independent variable and the dependent variable. To understand characteristic differences of age, gender, treatment class, and PSI class, chi-square test was used. To determine the effect of the independent variable on the dependent variable, a mean difference test was done in two groups using a t-test if the data distribution was normal and a Mann-Whitney test if the data distribution was not normal. To determine whether a relationship existed between the cofounding variable and the dependent variable, a Chi-square test was used. A logistic regression test was used to determine and predict the cofounding variables, including age, gender, accompanying diseases, degree of severity, and length of stay (LOS).

Cost-effectiveness was analyzed by determining the positions of the treatments under study on a cost-effectiveness diagram and comparing those positions with those of alternative treatments. The treatment cost of each group of antibiotics was compared by calculating the average cost-effectiveness ratio (ACER), which reflected the total direct medical cost spent by patients with CAP receiving inpatient care divided by antibiotic usage effectiveness or "success rate:"

\section{ACER $=\frac{\text { Total direct medical cost }}{\text { Success rate }}$}

Sensitivity analysis was done to determine how far cost changes or effectiveness used to calculate ACER can affect the conclusion.
Sensitivity analysis for antibiotic cost-effectiveness was done by increasing and decreasing the variation by $10 \%$ and $25 \%$ of the total cost.

\section{RESULTS}

There were 432 medical records in 2014-2016 in which CAP had been diagnosed; however, only 100 patients met the inclusion criteria and were thus included in this study. Of these 100 patients, 64 patients received empirical antibiotic therapy of intravenous (iv) ceftriaxone combination and azithromycin while 36 patients were treated with the empirical antibiotic of iv levofloxacin.

Descriptive data of the participants are presented in Table 1. The median age of patients with CAP who received empirical antibiotic therapy using ceftriaxone-azithromycin combination or levofloxacin from 2014 to 2016 was 59 years old; $50 \%$ of the patients were $>60$ years old. In the United States, it is estimated that there are around 5.2 million adult patients with CAP, and the majority of these individuals are above 65 years old ( 4.200 out of every 100.000 people) [8]. In the Netherlands, $45 \%$ of patients with CAP are above 65 years old [9]. Risk factors for CAP include old age and comorbidity. In geriatric populations, getting older is related to increased rates of contracting CAP, inpatient care, and death. Among around 1.1 million inpatients in hospitals due to pneumonia (including CAP) in 2007, 21\% were $45-64$ years old and 58\% were 65 years old or older. To reduce CAP risks, the IDSA and the ITS consensus guidelines recommend that individuals above 50 years old receive annual vaccination with inactive influenza virus and individuals who are 65 years and older receive a pneumococcus vaccination [10].

In this study, there were 51 male patients (51\%) and 49 female patients (49\%), with $43.8 \%$ male and $56.3 \%$ female patients in the ceftriaxoneazithromycin treatment group and $63.9 \%$ male and $36.1 \%$ female patients in the levofloxacin treatment group. This study consisted of patients with JKN at Persahabatan Hospital with a main diagnosis of CAP. According to the treatment class, there was no significant difference between the ceftriaxone-azithromycin group and the levofloxacin group, where Class III represented the most frequent treatment class: $67 \%$ of the total patients. In the ceftriaxone-azithromycin group, there was $3.1 \%$ Class I patients, $23.4 \%$ Class II patients, and $73.4 \%$ Class III patients. In the levofloxacin group, there was $8.3 \%$ Class I patients, $36.1 \%$ Class II patients, and 55.6\% Class III patients.

The conditions that were most comorbid with CAP among the patients in this study were hypertension (29\%) and diabetes mellitus $(25 \%)$ followed by acute chronic failure (16\%), heart failure (13\%), chronic obstructive pulmonary disease (COPD) (9\%), asthma (6\%), stroke $(6 \%)$, malignancy $(3 \%)$, and liver disease $(2 \%)$. Comorbidity is a risk factor in CAP. According to study by Torres et al., comorbid conditions including respiratory disease and chronic cardiovascular disease, cerebrovascular disease, Parkinson's disease, epilepsy, dementia, dysphagia, chronic kidney or liver disease, and even HIV can increase the risk of CAP by 2-4 times [11]. In the geriatric population, chronic diseases (diabetes mellitus, COPD, cancer, heart failure disease, and chronic kidney disease), age, and immune system can give not only lead to the contraction of a pneumonia infection but also to the development of a pneumonia infection, resulting in poor health outcomes [12]. In this study, the effectiveness parameter is based on the success rate, the LOS, and the LOS antibiotic-related LOSAR (Table 2). The success rate reflects whether the antibiotic resulted in successful treatment. The treatment is a success if the patient was cured or experienced clinical improvement, and the treatment was a failure if the patients died. LOS was calculated as the total days from the patient's first day at the hospital until discharge by doctor's agreement due to being cured or experiencing clinical improvement. LOSAR was calculated as the total number of days patients received iv empirical antibiotics. Patients who were discharged at their own demand were excluded from this study.

The dosages given to the combination therapy group were $1 \times 2$ gr iv and $1 \times 3$ gr iv of ceftriaxone and $1 \times 500 \mathrm{mg}$ per oral of azithromycin. The 
Table 1: Patients' characteristics organized by empirical antibiotics treatment at Persahabatan Hospital from 2014 to 2016

\begin{tabular}{|c|c|c|c|c|}
\hline Patient's characteristics & Total $(n=100)$ & Ceftriaxone iv and azithromycin $(n=64)$ & Levofloxacin iv (n=36) & p-value \\
\hline \multicolumn{5}{|l|}{ Age (\%) } \\
\hline $18-39$ years old & $9(9.0)$ & $5(7.8)$ & $4(11.1)$ & \multirow[t]{5}{*}{0.844} \\
\hline $40-59$ years old & $41(41.0)$ & $27(42.2)$ & $14(38.9)$ & \\
\hline$>60$ years old & $50(50.0)$ & $32(50.0)$ & $18(50.0)$ & \\
\hline Median & 59 & 59 & 59 & \\
\hline Range & $19-85$ & $19-85$ & $19-84$ & \\
\hline \multicolumn{5}{|l|}{ Gender (\%) } \\
\hline Male & $51(51.0)$ & $28(43.8)$ & $23(63.9)$ & \multirow[t]{2}{*}{0.063} \\
\hline Female & $49(49.0)$ & $36(56.3)$ & $13(36.1)$ & \\
\hline \multicolumn{5}{|l|}{ Degree of severity (\%) } \\
\hline PSI score & $83.2+26.7$ & $83.5+28.9$ & $82.6+22.5$ & 0.870 \\
\hline \multicolumn{5}{|l|}{ PSI class score $(\%)$} \\
\hline Class I & ND & ND & ND & \multirow[t]{5}{*}{0.879} \\
\hline Class II & $35(35.0)$ & $23(35.9)$ & $12(33.3)$ & \\
\hline Class III & $21(21.0)$ & $13(20.3)$ & $8(22.2)$ & \\
\hline Class IV & $43(43.0)$ & $27(42.2)$ & $16(44.4)$ & \\
\hline Class V & $1(1.0)$ & $1(1.6)$ & $0(0)$ & \\
\hline \multicolumn{5}{|l|}{ Inpatient care class $(\%)$} \\
\hline Class I & $5(5.0)$ & $2(3.1)$ & $3(8.3)$ & \multirow[t]{3}{*}{0.160} \\
\hline Class II & $28(28.0)$ & $15(23.4)$ & $13(36.1)$ & \\
\hline Class III & $67(67.0)$ & $47(73.4)$ & $20(55.6)$ & \\
\hline \multicolumn{5}{|l|}{ Comorbidity (\%) } \\
\hline Diabetes mellitus & $25(25.0)$ & $19(29.7)$ & $6(16.7)$ & 0.229 \\
\hline Hypertension & $29(29.0)$ & $19(29.7)$ & $10(27.8)$ & 1.000 \\
\hline Heart failure & $13(13.0)$ & $8(12.5)$ & $5(13.9)$ & 1.000 \\
\hline COPD & $9(9.0)$ & $4(6.3)$ & $5(13.9)$ & 0.277 \\
\hline Asthma & $6(6.0)$ & $1(1.6)$ & 5 (13.9) & $0.022^{*}$ \\
\hline Stroke & $6(6.0)$ & $4(6.3)$ & $2(5.6)$ & 1.000 \\
\hline Chronic kidney failure & $16(16.0)$ & $13(20.3)$ & $3(8.3)$ & 0.158 \\
\hline Liver disease & $2(2.0)$ & $2(3.1)$ & $0(0.0)$ & 0.535 \\
\hline Malignancy & $3(3.0)$ & $2(3.1)$ & $1(2.8)$ & 1.000 \\
\hline Amount of comorbidity (\%) & & & & 1.000 \\
\hline $0-1$ comorbidity & $68(68.0)$ & $43(67.2)$ & $25(69.4)$ & \\
\hline$>2$ comorbidity & $32(32.0)$ & $21(32.8)$ & $11(30.6)$ & \\
\hline
\end{tabular}

PSI: Pneumonia severity index, ND: Not defined, $\mathrm{p}$ value: Significance value, $\mathrm{p}$ value $>0.05$ there is no significant difference between the two groups, COPD: Chronic obstructive pulmonary disease, ${ }^{*} \mathrm{p}<0.05$, significant

Table 2: Effectiveness difference between the two treatment groups

\begin{tabular}{|c|c|c|c|c|}
\hline Parameter & Total $(n=100)$ & Ceftriaxone iv and azithromycin $(n=64)$ & Levofloxacin iv $(n=36)$ & p value \\
\hline \multicolumn{5}{|c|}{ Success rate (total) } \\
\hline Heal & $96(96.0)$ & $61(95.3)$ & $35(97.2)$ & 1.000 \\
\hline Dead & $4(4.0)$ & $3(4.7)$ & $1(2.8)$ & \\
\hline \multicolumn{5}{|l|}{ LOS (days) } \\
\hline Median & & 7 & 6 & $0.004^{*}$ \\
\hline Range & $2-14$ & $3-14$ & $2-11$ & \\
\hline \multicolumn{5}{|l|}{ LOSAR (days) } \\
\hline Range & $2-15$ & $3-15$ & $2-11$ & \\
\hline
\end{tabular}

LOS: Length of stay, LOSAR: Length of stay antibiotic-related, ${ }^{*} \mathrm{p}<0.05$, significant

dosage used for the levofloxacin group was $1 \times 750 \mathrm{mg}$ iv. According to the literature, a high dose of levofloxacin $(750 \mathrm{mg})$, produces similar results but in a shorter time than a dosage of $500 \mathrm{mg}$, especially for fever alleviation. In the ceftriaxone-azithromycin group, there were 3 patients $(4.7 \%)$ who died; in the levofloxacin group, 1 patient $(2.8 \%)$ died. The survival or success rates in both groups were not statistically significant (95.3\% and 97.2\%, respectively). A journal review by Raz-Pasteur et al. (2015) stated that there is no significant difference between fluoroquinolone antibiotics and beta-lactam/macrolide in the total number of deaths: RR (95\%, CI) 0.99 (0.70-1.40) [13]. A meta-analysis done by Skalsky et al. stated that there is no significant difference in the mortality rate between quinolone groups and monotherapy macrolide or combination with beta-lactam RR (1.03. 95\%, CI: 0.63-1.68) [14].

To investigate the effect of LOS using PSI score, age, gender, total and type of comorbidity, chi-square test was used. As shown in the results in Table 3, there was a significant relationship between LOS and degree of severity (PSI class) $(\mathrm{p}=0.022)$. Meanwhile, the results did not show a significant relationship between LOS and age $(p=0.840)$, total of comorbidity $(\mathrm{p}=0.665)$, gender $(\mathrm{p}=0.686)$, presence (present or not present) of diabetes mellitus comorbidity ( $\mathrm{p}=0.665)$, presence (present or not present of hypertension comorbidity $(\mathrm{p}=0.824)$, presence (present or not present) of heart failure comorbidity $(\mathrm{p}=0.228)$, presence (present or not present) of stroke comorbidity $(p=0.235)$, presence (present or not present) of asthma comorbidity $(\mathrm{p}=0.080)$, presence (present or not present) of COPD comorbidity $(p=0.486)$, presence (present or not present) of acute kidney failure comorbidity $(\mathrm{p}=0.787)$, presence (present or not present) of heart disease comorbidity $(\mathrm{p}=0.508)$, and presence (present or not present) of malignancy comorbidity $(p=1.000)$. Based on bivariate analysis, a multivariate analysis with logistic regression of the confounding factors was conducted with a $\mathrm{p}<0.25$. The results showed that degree of severity, especially Classes IV and V PSI was significantly related to LOS ( $\mathrm{p}=0.020$, OR: 2.963 with 95\%, CI: 1.185-7.409). 
Table 3: Bivariate analysis to determine the effects of confounding factors on LOS

\begin{tabular}{|c|c|c|c|}
\hline \multirow[t]{2}{*}{ Confounding } & \multicolumn{2}{|c|}{ LOS ( $<7$ days) } & \multirow[t]{2}{*}{ p-value } \\
\hline & n (\%) & n (\%) & \\
\hline \multicolumn{4}{|l|}{ Degree of severity } \\
\hline Class II and III PSI & $30(53.6)$ & $26(46.4)$ & \multirow[t]{2}{*}{$0.014^{*}$} \\
\hline Class IV and V PSI & $12(27.3)$ & $32(72.7)$ & \\
\hline \multicolumn{4}{|l|}{ Age } \\
\hline$<60$ years old & $22(44.0)$ & $28(56.0)$ & \multirow[t]{2}{*}{0.840} \\
\hline$>60$ years old & $20(40.0)$ & $30(60.0)$ & \\
\hline \multicolumn{4}{|l|}{ Gender } \\
\hline Male & $20(39.2)$ & $31(60.8)$ & \multirow[t]{2}{*}{0.686} \\
\hline Female & $22(44.9)$ & $27(55.1)$ & \\
\hline \multicolumn{4}{|l|}{ Total of comorbidity } \\
\hline$<2$ comorbidity & $30(44.1)$ & $38(55.9)$ & \multirow[t]{2}{*}{0.665} \\
\hline$>2$ comorbidity & $12(37.5)$ & $20(62.5)$ & \\
\hline \multicolumn{4}{|c|}{ Presence of diabetes mellitus } \\
\hline Not present & $33(44.0)$ & $42(56.0)$ & \multirow[t]{2}{*}{0.640} \\
\hline Present & $9(36.0)$ & $16(64.0)$ & \\
\hline \multicolumn{4}{|c|}{ Presence of hypertension } \\
\hline Not present & $29(40.8)$ & $42(59.2)$ & \multirow[t]{2}{*}{0.824} \\
\hline Present & $13(44.8)$ & $16(55.2)$ & \\
\hline \multicolumn{4}{|l|}{ Presence of $\mathrm{CHF}$} \\
\hline Not present & $39(44.8)$ & $48(55.2)$ & \multirow[t]{2}{*}{$0.228^{*}$} \\
\hline Present & $3(23.1)$ & $10(76.9)$ & \\
\hline \multicolumn{4}{|l|}{ Presence of stroke } \\
\hline Not present & $38(40.4)$ & $56(59.6)$ & \multirow[t]{2}{*}{$0.235^{*}$} \\
\hline Present & $4(66.7)$ & $2(33.3)$ & \\
\hline \multicolumn{4}{|l|}{ Presence of asthma } \\
\hline Not present & $37(39.4)$ & $57(60.6)$ & \multirow[t]{2}{*}{$0.080^{*}$} \\
\hline Present & $5(83.3)$ & $1(16.7)$ & \\
\hline \multicolumn{4}{|l|}{ Presence of COPD } \\
\hline Not present & $37(40.7)$ & $54(59.3)$ & \multirow[t]{2}{*}{0.486} \\
\hline Present & $5(55.6)$ & $4(44.4)$ & \\
\hline \multicolumn{4}{|l|}{ Presence of AKI } \\
\hline Not present & $36(42.9)$ & $48(57.1)$ & \multirow[t]{2}{*}{0.787} \\
\hline Present & $6(37.5)$ & $10(62.5)$ & \\
\hline \multicolumn{4}{|c|}{ Presence of malignancy } \\
\hline Not present & $41(42.3)$ & $56(57.7)$ & \multirow[t]{2}{*}{1.000} \\
\hline Present & $1(33.3)$ & $2(66.7)$ & \\
\hline Presence of heart dis & & & \\
\hline Not present & $42(42.9)$ & $56(57.1)$ & 0.508 \\
\hline Present & $0(0.0)$ & $2(100.0)$ & \\
\hline
\end{tabular}

Table 4 shows the cost component analysis from each treatment group. The two empirical antibiotics groups were significantly different in price. The price of ceftriaxone-azithromycin was less than that of levofloxacin. As known, the drugs supply in the National Health Insurance Scheme is organized based on a national e-catalog for drugs majority the e-catalog is an electronic information system that lists the drugs' type, technical specification, and stock price from several suppliers. Based on the e-catalog, the price of infusion levofloxacin per unit is Rp.22.318 in DKI Jakarta while the price of injection ceftriaxone is Rp.3.300 and 1.888 for azithromycin; Table 4 demonstrates that there is significant difference between the two antibiotics in terms of price.

Other costs that were analyzed were room cost, doctor's visit cost, drugs cost, adjunctive examination cost, and treatment cost. There was no significant difference between doctor's visit costs, room cost, and treatment cost. The patients included in the group were from treatment Classes I-III, and the composition was not statistically significant between each class. In room cost analysis, there was no significant difference between the ceftriaxone-azithromycin group and the levofloxacin group. In adjunctive examination, there was a significant difference between each group. In the different treatment classes, there was a statistical difference in the tariffs of the room cost and doctor's
Table 4: Direct medical cost distribution between the two treatment groups

\begin{tabular}{|c|c|c|c|}
\hline \multirow[t]{2}{*}{ Parameter } & \multicolumn{2}{|c|}{ Cost median (rupiah) } & \multirow[t]{2}{*}{ p-value } \\
\hline & $\begin{array}{l}\text { Ceftriaxone } \\
\text { iv and } \\
\text { azithromycin }\end{array}$ & Levofloxacin iv & \\
\hline $\begin{array}{l}\text { Empirical antibiotic } \\
\text { cost }\end{array}$ & Rp. 130.756 & Rp. 286.952 & $0.000 *$ \\
\hline Room cost & Rp. 675.000 & Rp. 570.428 & 0.334 \\
\hline Doctor's visit cost & Rp. 568.456 & Rp. 502.779 & 0.703 \\
\hline Drugs cost & Rp. 1.093.844 & Rp. 1.012 .074 & 0.239 \\
\hline $\begin{array}{l}\text { Adjunctive } \\
\text { examination cost }\end{array}$ & Rp. 2.232.492 & Rp. 1.304 .804 & $0.000 *$ \\
\hline Treatment cost & Rp. 741.716 & Rp. 791.961 & 0.977 \\
\hline Other cost & Rp. 172.744 & Rp. 383.851 & 0.071 \\
\hline $\begin{array}{l}\text { Total direct medical } \\
\text { cost }\end{array}$ & Rp. 6.494 .988 & Rp. 5.444.242 & 0.082 \\
\hline
\end{tabular}

Table 5: ACER calculation of each antibiotic group

\begin{tabular}{llll}
\hline $\begin{array}{l}\text { Empirical } \\
\text { antibiotic type }\end{array}$ & Cost (C) & $\begin{array}{l}\text { Effectiveness } \\
\text { (E) }\end{array}$ & ACER (C/E) \\
\hline $\begin{array}{l}\text { Ceftriaxone iv } \\
\text { and azithromycin }\end{array}$ & Rp. 6.494.988 & 95.3 & $\begin{array}{l}\text { Rp. 68.153\% } \\
\text { effectiveness }\end{array}$ \\
$\begin{array}{l}\text { Levofloxacin iv } \\
\text { Rp. 5.444.242 }\end{array}$ & 97.2 & $\begin{array}{l}\text { Rp. 56.011\% } \\
\text { effectiveness }\end{array}$ \\
\hline
\end{tabular}

visit cost, but not in adjunctive examination. In this study, differences in adjunctive examination cost could have been affected by each group's LOS, as patients required varying levels of adjunctive examination.

CER was done by comparing total cost (C) to effectiveness (E) in each treatment group. The result was interpreted as mean effectiveness per unit. The lower the cost was, the higher the effectiveness from the $\mathrm{C} / \mathrm{E}$ ratio and the investment value obtained from that intervention was; therefore, this strategy is chosen [15]. The total cost reflected the total cost of each treatment median while effectiveness referred to the treatment success rate (cured or clinical improvement). The results of the CER calculation can be seen in Table 4. The calculation in Table 5 shows that the ACER value of the ceftriaxone-azithromycin group is Rp.68.153\% effectiveness, which is higher than the ACER value of the levofloxacin group, which was Rp.56.011\% effectiveness. Therefore, levofloxacin is considered more cost-effective than ceftriaxoneazithromycin combination.

A cost-effectiveness grid can be used to define cost-effectiveness. To understand a treatment or cost-effective service, cost and effectiveness should be calculated. If an alternative treatment is more effective and has a lower cost (cell G), is more effective but has the same cost (cell H), or has the same effectiveness and a lower cost (cell D), that treatment can be defined as cost-effective. However, if an alternative treatment is less effective and has a higher cost (cell $\mathrm{C}$ ), has the same effectiveness but also has a higher cost (cell F), or has less effectiveness and the same cost (cell B), that drug is not considered cost effective (Table 6) [15].

The results of the sensitivity analysis show that choosing levofloxacin is sensitive to a $25 \%$ increase in cost, and this increase in cost yields a higher ACER result than the baseline ceftriaxone-azithromycin ACER value (Table 7). Choosing levofloxacin is sensitive to a $25 \%$ decrease in the cost of the ceftriaxone-azithromycin group, and this decrease in cost yields a lower ACER result in the levofloxacin group than the baseline ACER value.

\section{DISCUSSION}

This study examined the cost-effectiveness of ceftriaxoneazithromycin combination and single levofloxacin as empirical 
Table 6: Position of levofloxacin and ceftriaxone-azithromycin on a cost-effectiveness grid

\begin{tabular}{llll}
\hline Cost-effectiveness & Lower cost & Same cost & Higher cost \\
\hline Lower effectiveness & A ICER calculation & B & C dominated (ceftriaxone-azithromycin) \\
Same effectiveness & D & E arbitrary & F \\
Higher effectiveness & G dominant(levofloxacin) & H & I ICER calculation \\
\hline
\end{tabular}

Table 7: Sensitivity analysis calculation between the two treatment groups

\begin{tabular}{llll}
\hline Sensitivity & Cost (C) & Effectiveness & ACER (C/E) \\
\hline $\begin{array}{l}\text { Ceftriaxone and } \\
\text { azithromycin (\%) }\end{array}$ & & & \\
Decrease of 0 & Rp. 6.494.988 & 95.3 & Rp. 68.153 \\
Decrease of 10 & Rp. 5.845.489 & 95.3 & Rp. 61.338 \\
Increase of 10 & Rp. 6.430.038 & 95.3 & Rp. 67.472 \\
Decrease of 25 & Rp. 4.871.241 & 95.3 & Rp. 51.115 \\
Increase of 25 & Rp. 8.118.735 & 95.3 & Rp. 85.191 \\
Levofloxacin (\%) & & & \\
Decrease of 0 & Rp. 5444242 & 97.2 & Rp. 56.011 \\
Decrease of 10 & Rp. 4899818 & 97.2 & Rp. 50.410 \\
Increase of 10 & Rp. 5389800 & 97.2 & Rp. 55.451 \\
Decrease of 25 & Rp. 4083182 & 97.2 & Rp. 42.008 \\
Increase of 25 & Rp. 6805303 & 97.2 & Rp. 70.013 \\
\hline
\end{tabular}

antibiotics for treating inpatients with CAP. The cost-effectiveness analysis was done by comparing the direct total medical cost to effectiveness, which was determined by the success rate in each treatment group. In this study, there was a significant difference in LOS between the two groups. The median LOS in the levofloxacin group was 6 days, while the median LOS in the ceftriaxoneazithromycin was 7 days. There was also a significant difference between the two groups in the LOSAR. The LOSAR median in the patients who received levofloxacin was 5 days, whereas the LOSAR median in the patients who received ceftriaxone-azithromycin was 6 days. This is in agreement with a previous study by Lodise et al., who stated that there was a significant difference in the LOS between the beta-lactam-macrolide group and the fluoroquinolone group (LOS median was 6 days and 5 days, respectively) [16]. A study done by Querol-Ribelles et al. stated that the median LOS for levofloxacin was 5 days, while the median LOS for ceftriaxone-clarithromycin was 6 days, but no significant difference was found [17]. According to a meta-analysis conducted by Vardakas et al., the LOS for patients who received fluoroquinolone was 1-2 days shorter than patients who received antibiotics of macrolide or beta-lactam or a combination of both [18].

Some studies have investigated the relation between length of treatment and degree of severity in patients with CAP. Menendez et al. found a positive relationship between LOS and PSI score, pleura effusion, and blood urea nitrogen concentration and found no correlation between LOS and age, gender, alcohol intake, smoking cigarettes, and comorbidity [19]. A study by Garau et al. also found a significant relationship between LOS and death as well as LOS and PSI score (especially in Classes IV and V PSI, positive blood culture, ICU admission, and alcohol consumption) in patients with CAP [20]. The results of the current study are in agreement with the two previous studies, as the current study found a significant relationship between LOS and PSI score (degree of severity) [14].

Cost analysis was done to understand the total cost components in both treatment groups [15]. The costs included in this study were antibiotic cost, total drugs cost, doctor's visit cost, treatment cost, and adjunctive examination cost. These costs are categorized as direct medical costs, which refer to the costs counted most often and are used directly to provide treatment [15]. According to the results, the effectiveness of levofloxacin therapy is higher than that of ceftriaxoneazithromycin, and the direct medical cost of levofloxacin is lower than that of ceftriaxone-azithromycin; therefore, in the cost-effectiveness grid, levofloxacin is in the dominant group. In this case, there is no need to calculate the ICER because it can be concluded that levofloxacin is more cost-effective.

This study has several limitations. First, this study was conducted retrospectively from medical records, thus limiting the total number of participants. Second, this study did not compare across treatment classes due to the minimal total sample. According to cost-effectiveness analysis, levofloxacin care (with an ACER value of Rp.56.011\%) is more cost-effective than ceftriaxone and azithromycin combination antibiotics (with an ACER value of Rp.68.153\% effectiveness) for treating inpatients with CAP.

\section{REFERENCES}

1. Menendez R, Reyes S, Martinez R, de la Cuadra P, Valles JM, Vallterra J. Economic evaluation of adherence to treatment guidelines in non-intensive care pneumonia. Eur Respir J 2007;29:751-6.

2. Alldredge K, Corelli RL, Ernst ME. Applied Therapeutics, the Clinical use of Drugs. $10^{\text {th }}$ ed. Philadelphia, PA: Lippincott Williams \& Wilkins; 2013.

3. Vigg A. Severe community acquired pneumonia (SCAP). Apollo Med 2016;13(1):17-9.

4. Indonesian Pulmonologist Association. Pneumonia Komunitas. Jakarta: Pedoman Diagnosis dan Penatalaksanaan di Indonesia; 2014.

5. Mandell LA, Wunderink RG, Anzueto A, Bartlett JG, Campbell GD, Dean NC, et al. Infectious Diseases Society of America/American Thoracic Society consensus guidelines on the management of community-acquired pneumonia in adults. Clin Infect Dis 2007;44 Suppl 2:S27-72.

6. Bhavnani SM, Ambrose PG. Cost-effectiveness of oral gemifloxacin versus intravenous ceftriaxone followed by oral cefuroxime with/ without a macrolide for the treatment of hospitalized patients with community-acquired pneumonia. Diagn Microbiol Infect Dis 2008;60(1):59-64.

7. Dresser LD, Niederman MS, Paladino JA. Cost-effectiveness of gatifloxacin vs ceftriaxone with a macrolide for the treatment of community-acquired pneumonia. Chest 2001;119(5):1439-48.

8. Shea KM, Weycker D, Stevenson AE, Strutton DR, Pelton SI. Modeling the decline in pneumococcal acute otitis media following the introduction of pneumococcal conjugate vaccines in the US. Vaccine 2011;29(45):8042-8.

9. Rozenbaum MH, Mangen MJ, Huijts SM, van der Werf TS, Postma MJ. Incidence, direct costs and duration of hospitalization of patients hospitalized with community acquired pneumonia: A nationwide retrospective claims database analysis. Vaccine 2015;33(28):3193-9.

10. Sato R, Gomez Rey G, Nelson S, Pinsky B. Community-acquired pneumonia episode costs by age and risk in commercially insured US adults aged $=50$ years. Appl Health Econ Health Policy 2013;11(3):251-8

11. Torres A, Peetermans WE, Viegi G, Blasi F. Risk factors for communityacquired pneumonia in adults in Europe: A literature review. Thorax 2013;68(11):1057-65.

12. González-Castillo J, Martín-Sánchez FJ, Llinares P, Menéndez R, Mujal A, Navas E, et al. Guidelines for the management of communityacquired pneumonia in the elderly patient. Rev Esp Quimioter 2014;27(1):69-86

13. Indonesian Ministry of Health. Basic Health Survey. Mumbai: Indonesian Ministry of Health; 2013.

14. Skalsky K, Yahav D, Lador A, Eliakim-Raz N, Leibovici L, Paul M. Macrolides versus quinolones for community-acquired pneumonia: Meta-analysis of randomized controlled trials. Clin Microbiol Infect 2012;19(4):370-8

15. Andayani TM. Farmakoekonomi Prinsip dan Metodologi. Yogyakarta: Bursa Ilmu; 2013

16. Lodise TP, Kwa A, Cosler L, Gupta R, Smith RP. Comparison of 
beta-lactam and macrolide combination therapy versus fluoroquinolone monotherapy in hospitalized Veterans Affairs patients with community-acquired pneumonia. Antimicrob Agents Chemother 2007;51(11):3977-82.

17. Querol-Ribelles JM, Tenías JM, Querol-Borrás JM, Labrador T, Nieto A, González-Granda D, et al. Levofloxacin versus ceftriaxone plus clarithromycin in the treatment of adults with communityacquired pneumonia requiring hospitalization. Int J Antimicrob Agents 2005;25(1):75-83

18. Vardakas KZ, Siempos II, Grammatikos A, Athanassa Z, Korbila IP,
Falagas ME. Respiratory fluoroquinolones for the treatment of community-acquired pneumonia: A meta-analysis of randomized controlled trials. CMAJ 2008;179(12):1269-77.

19. Menéndez R, Cremades MJ, Martínez-Moragón E, Soler JJ, Reyes S, Perpiñá M. Duration of length of stay in pneumonia: Influence of clinical factors and hospital type. Eur Respir J 2003;22(4):643-8.

20. Garau J, Baquero F, Pérez-Trallero E, Pérez JL, Martín-Sánchez AM, García-Rey C, et al. Factors impacting on length of stay and mortality of community-acquired pneumonia. Clin Microbiol Infect 2008; 14:322-9. 